\title{
Silver Staining of Alzheimer's Disease
}

\section{Orwa Aboud ${ }^{1,2^{*}}$ and Sue T. Griffin $\mathbf{W}^{1,3}$}

${ }^{1}$ Donald W. Reynolds Department of Geriatrics, University of Arkansas for Medical Sciences, Little Rock, AR, USA

${ }^{2}$ Department of Neurology, University of Arkansas for Medical Sciences, Little Rock, AR, USA

3Geriatric Research, Education, Clinical Center, Central Arkansas HealthCare System, Little Rock, AR, USA

"Corresponding author: Orwa Aboud, University of Arkansas for Medical Sciences, Donald W. Reynolds Department of Geriatrics, 629 Jack Stephens Drive, Little Rock, Arkansas 72205, Tel: 501-526-5800; Fax: 501-526-5830; E-mail: oaboud@uams.edu

Rec date: Oct 23, 2014, Acc date: Oct 26, 2014, Pub date: Oct 28, 2014

Copyright: (c) 2014 Aboud O, et al. This is an open-access article distributed under the terms of the Creative Commons Attribution License, which permits unrestricted use, distribution, and reproduction in any medium, provided the original author and source are credited.

\section{Description}

Sliver stain of olfactory bulb tissue section in a 74 year old male with a clinical history of Alzheimer's, congestive heart failure, and pneumonia. A. A $10 \mathrm{X}$ magnification for the area containing the anterior olfactory nucleus (AON) (astercs). B. A 20X of the same area showing neurofibrillary tangles (arrow) and neuropil threads (double arrow).

The autopsy showed definite Alzheimer's disease (C on CERAD scale). Neuritic plaques identified in inferior parietal and parahippocampal areas from this patient. There were moderate tangles in peristriate and frontal cortex, and neuropil threads were prominent in mesial temporal structures and frontal cortex.

Paraffin sections were deparaffinized and hydrated to distilled water, then placed in $20 \%$ silver nitrate and kept in $60^{\circ} \mathrm{C}$ for 15 minutes, then rinsed in distilled water. Then sections were treated with formalin solution containing ammoniacal silver solution for about $15 \mathrm{~min}$, followed by rinsing and placing tissue in sodium thiosulfate solution for 2 minutes and washing in tap water. The section then were dehydrated and mounted with synthetic resin.

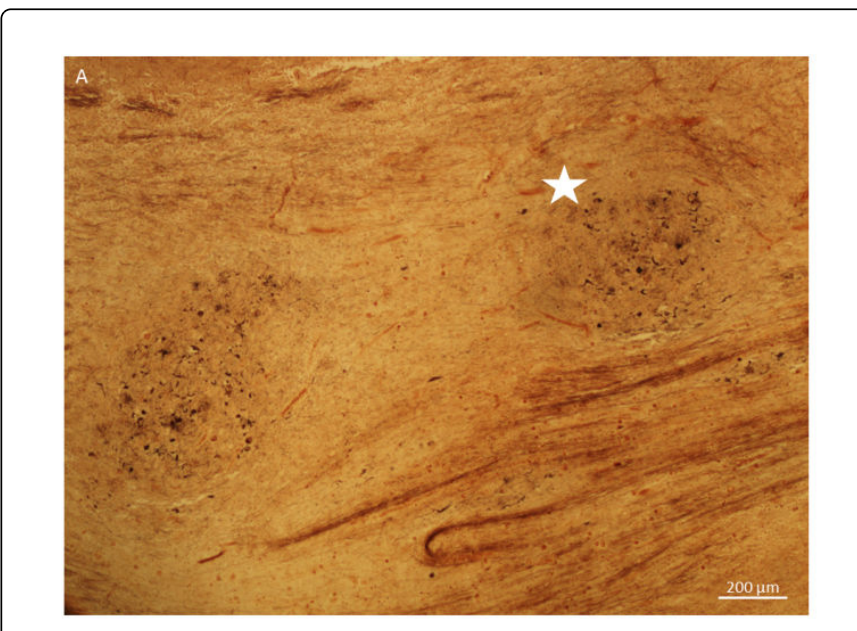

Figure 1A: 10X magnification for the area containing the anterior olfactory nucleus (AON) (astercs). 